\title{
Editorial
}

\section{Geriatric care: Need of the hour}

\author{
Air Cmde V.K. Sashindran \\ Professor \& Head, Department of Internal Medicine, Armed Forces Medical College, Pune 411040, India
}

As we hurtle towards the end of the second decade of the twenty-first century, a rapid demographic transition is occurring globally. For the first time in history, the elderly have become the fastest growing segment of the population. The global share of older people (>60 yrs) has increased from $9.2 \%$ in 1990 to $11.7 \%$ in 2013 and is predicted to be $21.1 \%$ by $2050 .^{1}$ India has not remained untouched by this global trend. According to the United Nations Development Programme report of 2011, life expectancy at birth was more than 65 yrs in only four states (Kerala, Karnataka, Maharashtra and Tamil Nadu) in the period from 2002 to 2006. ${ }^{2}$ Ponnapali et al. published a study on demographic transition in India in 2013. They reported that between 2011 and 2016 India's average life expectancy would be 66.8 years, only 3.2 years short of the global life expectancy of 70 years and that only four states would have a projected life expectancy at birth below 65 years. ${ }^{3}$ These studies have been validated by the latest report by Social Statistics division of Government of India of 2016 which pegs the life expectancy at birth today at 69.3 years for females and 65.8 years for males. ${ }^{4}$ By 2050 , it is estimated that India's elderly population will be 323 million, a number that will be more than the entire population of the United States. ${ }^{5}$ This rapid change is best described in an article published in the Times of India which said that average life expectancy had gone up from 42 years in 1980 to 62 in 2000. And that in the decade between 2005 and 2015 average life expectancy had increased by 5 years from 62.3 to 67.3 for males and from 63.9 to 69.6 years for females. ${ }^{6}$ In a study published in Medical Journal Armed Forces India in 1998, Bhalwar et al. used mathematical modelling to predict trends in the age of exservicemen population. They said that by 2015, the segment of veteran aged $>65$ years would overtake the segment of 50-64 years and that by 2027 , they would constitute $34 \%$ of the exserviceman population. Despite these predictions, little has been done to address the healthcare needs of elderly people. ${ }^{7}$

As a nation we have not anticipated this demographic change and created a safety net for the elderly. Seventy one percent of the Indian elderly reside in rural settings. Bereft of social security schemes a significant proportion have to work (66\% males and $28 \%$ females in rural areas and $46 \%$ males and $11 \%$ females in urban setting). ${ }^{4}$ Old age dependency has increased and varies from 313/1000 elderly people in rural areas to $297 / 1000$ in urban areas. Seventy-five percent of the elderly are supported by their children or grand children. ${ }^{8}$ It is not surprising that $14 \%$ of the elderly are victims of abuse. ${ }^{9}$

Ten percent of the people $>60$ yrs are physically impaired and $8 \%$ are confined to the bed or their homes and $10 \%$ are hospitalised at any time. ${ }^{10,11}$ Amongst people more than 70yrs-old, 50\% have more than one chronic condition requiring lifelong medication. Almost half of the disabled elderly have locomotor or visual problems. ${ }^{4}$ A morbidity survey among elderly people of rural Tamil Nadu showed that $57 \%$ have decreased visual acuity, $43.4 \%$ have joint pain and stiffness, $42 \%$ have difficulty in chewing and $15.4 \%$ have hearing impairment. Hypertension, diabetes and heart disease are seen in $14 \%, 9 \%$ and $8.1 \%$ respectively. ${ }^{12}$ Another study from rural Karnataka shows that $33 \%$ of the elderly scored above the threshold for mental illness on the Global Health Questionnaire (GHQ)-12; with $21.9 \%$ having depression, $10.7 \%$ generalised anxiety and $16.3 \%$ cognitive impairment. ${ }^{13}$ The three top causes of elderly mortality are cardiovascular diseases (33\%), respiratory diseases (10\%) and infections including tuberculosis $(10 \%){ }^{14}$

Medical fraternity in the West noted this ageing trend almost three-quarters of a century earlier. The American Geriatric Society was founded in 1942. In the United Kingdom, Geriatrics has been recognised as a distinct subspecialty of Medicine since the 1970s. The first geriatric outpatient facility in India was set up in Madras Medical College Hospital in 1978 and in-patient care started in 1988. The first MD Geriatrics programme was also started in Madras Medical College in 1996. Today, five institutions offer post-graduates courses in geriatrics. This is clearly too little and too late. Recognising this crisis, the Government of India launched the National

E-mail address: vksashindran@gmail.com.

https://doi.org/10.1016/j.mjafi.2017.12.007

0377-1237/@ 2017 Published by Elsevier B.V. on behalf of Director General, Armed Forces Medical Services. 
Programme for Health Care of the Elderly (NPHCE) in 2010. This programme aims to create a 'new architecture for ageing'. The objectives of the programme include provision of accessible, affordable, high quality, long-term, comprehensive and dedicated services for an ageing population. The capacity building is supposed to start at the grass-root level with equipment, training and additional human resources being provided to community and primary health centres. At the next level, 10-bedded geriatric wards will be set up in district hospitals. Public awareness programs and domiciliary visit by trained health care workers are other features. Many hospitals in Bikaner, Bengaluru, Cochin, Delhi, Jodhpur, Kolkata, Lucknow, Manipal, Mumbai and Vellore have weekly geriatric clinics. Sunday clinics are another innovation facilitating relatives to take the elderly to hospitals. Separate queues in hospitals have become commonplace. But facilities for geriatric care are still woefully inadequate in most public hospitals. Ramps, seating with arm rests, and toilets with support rails are yet to become the rule rather than the exception. A set of criteria to assess 'senior friendliness' hospitals in India have been developed and validated. ${ }^{15}$ It can serve as a starting point to assess our hospitals and plan modifications. State governments have launched many geriatric welfare programmes. These include provision of free spectacles and intra-ocular lenses in Goa, Gujarat, and Rajasthan and many health insurance schemes targeting senior citizens. Elderly care has to become multi-disciplinary with strong preventive, palliative and rehabilitative elements factored into it.

The main challenge is not only to improve healthcare delivery to the elderly but also to make their quality of life better. The Japanese, have the highest life-expectancy in the world today. This is not only due to their health services but also due to their attempts to integrate their elder people into mainstream society. The prefectural governments have special health promotion programmes for the elderly which not only focus on diet but also regular physical activity. The Japanese Food Guide Spinning Top model has been validated by the Japan Public health Center. They found that a higher score was associated with lower overall mortality over a 15 year follow up period. ${ }^{16}$ Second careers as post office staff, tourist bureau staff and school teachers are offered to the elderly. By offering suitable employment to the elderly, the Japanese have addressed social isolation, and the sense of uselessness which creeps in after retirement. In middle-class India, we tend to treat our elders with a sense of guilt. For having worked hard to provide for the children, the latter, in return, tell them to rest. While the young get busy with their lives, the elderly, despite all the material comforts, careen towards depression and loneliness. But, for the poor, there is no such luxury. Many have to ignore infirmities and continue to work to make ends meet. Without social security, health insurance or social support, their lives are precarious and filled with anxiety.

Clearly, the challenge of elder care is not just medical but also psychological, social and economic. There will be no quick fix solutions, and a lot of planning, financial outlay and commitment will be needed. We, too will grey and retire. Do we want this for ourselves? As Dr. B. Krishnaswamy, the doyen of Geriatric Medicine in India said, "Yes, we will live longer, but the big question is how healthy our lives will be."

\section{R E F E R E N C E S}

1. Oeppen J, Vaupel JW. Broken limits to life expectancy. Science. 2002;296(May (5570)):1029-1031 [PubMed: 12004104].

2. Nanda AR, Haub C. The future population of India - a long range demographic view. Popul Res Bureau. 2007.

3. Ponnapalli R, Ponnapalli KM, Subbiah A. Aging and the demographic transition in India and its states: a comparative perspective. Int J Asian Soc Sci. 2013;3(1):171-193.

4. Elderly in India-Profile and Programmes 2016. New Delhi: Ministry of Statistics and Programme Implementation. Government of India; 2016.

5. Ingle GK, Nath A. Concerns and solutions for problems in geriatric health in India. Indian J Community Med. 2008;33 (4):214-218.

6. Sampath J. Life expectancy in India goes up by 5 years in a decade. Times of India. 29 January 2014.

7. Bhalwar R, Basannar DR, Sharma Al. Estimates of exservicemen population for the next 30 years: a need to reorient our health planning. MJAFI. 1998;54:328-330.

8. Morbidity, Health Care and Condition of the Aged. National Sample Survey 60th Round (January to June 2004). Government of India; 2006, March:54-65.

9. Chokkanathan S, Lee AE. Elder-mistreatment in Urban India: a community based study. J Elder Abuse Negl. 2005;17:45-61.

10. Reddy PH. The health of the aged in India. Health Transit Rev. 1996;6:233-244.

11. Verma R, Khanna P. National program of health-care for the elderly in India: a hope for healthy ageing. Int J Prevent Med. 2013;4(10):1103-1110.

12. Purty AJ, Bazroy J, Kar M, Vasudevan K, Veliath A, Panda P. Morbidity pattern among the elderly population in the rural area of Tamil Nadu, India. Turk J Med Sci. 2006;36:45-50.

13. Nair S, Pooja R, Sreekanth SN. Prevalence of psychiatric disorders among the rural geriatric population: a pilot study in Karnataka, India. Central Asian J Global Health. 2015;4.

14. Morbidity related epidemiological determinants in Indian aged: an overview.Ramachandran CR, Shah B, eds. Public Health Implications of Ageing in India. New Delhi: Indian Council of Medical Research; 1994.

15. Rashmi MR, Kasthuri A, Rodrigues RJ. Senior friendly hospitals: development and application of criteria: a descriptive study. Indian J Community Med. 2016;41:256-262.

16. Kurotani K, Akter S, Kashino I, et al. Quality of diet and mortality among Japanese Men and women: Japan Public Health Centre based prospective study. BMJ. 2016;352:i1209. 